\title{
Modeling daily production of aquatic macrophytes from irradiance measurements: a comparative analysis
}

\author{
Richard C. Zimmerman ${ }^{1, *}$, Alejandro Cabello-Pasini ${ }^{2}$, Randall S. Alberte ${ }^{1,3}$ \\ ${ }^{1}$ Department of Biology, University of California at Los Angeles, Los Angeles, California 90024, USA \\ ${ }^{2}$ Marine Sciences Research Center, State University of New York, Stony Brook, New York 11794, USA \\ ${ }^{3}$ Biological Science and Technology Program, Office of Naval Research, Arlington, Virginia 22217, USA
}

\begin{abstract}
The importance of submerged aquatic macrophytes to coastal ecosystems has generated a need for knowledge of minimum light levels that will support the maintenance and restoration of healthy populations. Our goals were (1) to evaluate the sensitivity to natural, non-sinusoidal fluctuations in irradiance $I$ of analytical integration techniques for calculating daily carbon gain, (2) to evaluate the $H_{5+1}$ (the daily period of $I$-saturated photosynthesis) model of daily production relative to models based on instantaneous photosynthesis vs irradiance ( $P$ vs $I$ ) and (3) to provide some guidance for the temporal density of irradiance data required for accurate estimation of daily carbon gain. Monthly measures of the P vs I response of an eelgrass Zostera marina $L$. population were used to predict rates of daily carbon gain from continuous in situ recordings of $I$. Daily integrated $I$ was not a reliable predictor of daily production. Numerical (iterative) integration of $H_{\text {sat }}$ was much more reliable but required repeated measures of $I$ within a day, as did numerical integration of $P$ vs $I$. Analytical (non-iterative) models based only on observations of $I_{m}$ (noon) could not predict daily production accurately. Analytical models of $P$ vs $I$ and $H_{\text {sat }}$ agreed with each other, however, indicating that the analytical models may be useful where the daily pattern of $I$ is sinusoidal. Given the high degree of temporal variability in coastal light environments, continuous monitoring of light availability may be required for calculation of daily production and reliable management of aquatic macrophyte populations
\end{abstract}

KEY WORDS: Light requirements - Photosynthesis - Primary productivity - Seagrasses - Submerged aquatic macrophytes . Carbon budget $\cdot H_{\text {sat }}$

\section{INTRODUCTION}

Light availability is the most important factor regulating the depth distribution, abundance and productivity of submerged aquatic macrophytes (SAM) that inhabit critical, yet extremely fragile, ecosystems in shallow coastal embayments and estuaries throughout the world (e.g. Backman \& Barilotti 1976, Dennison \& Alberte 1982, 1985, 1986, Duarte 1991). Estuaries are vulnerable to anthropogenic alteration of water quality, particularly with regard to light availability. Increased turbidity caused by eutrophication, chronic upstream erosion and periodic dredging has dramati-

-Address for correspondence: Hopkins Marine Station, Pacific Grove, California 93950, USA cally reduced light penetration in many estuarine water columns, thereby reducing the depth distribution, density and productivity of SAM (Zieman 1975 , Orth \& Moore 1983, Cambridge \& McComb 1984, Shepherd et al. 1989, Carter \& Rybicki 1990, Larkum \& West 1990, Zimmerman et al. 1991, Monroe et al. 1992).

Protection of SAM in coastal environments requires a shift in management emphasis from monitoring environmental deterioration to the improvement of coastal zone water quality so that critical macrophytebased ecosystems can be maintained and even expanded (Dennison et al 1993). To that end, submarine irradiance $(I$, photosynthetically active radiation) has become a routinely measured parameter of water quality (Batiuk et al. 1993, Morris \& Tomasko 1993, Dring \& Lüning 1994). 
Light attenuation coefficients and instantaneous submarine $I$ are relatively easy to measure, and light requirements of SAM have been calculated from the generally observed correlation between the mean coefficient of diffuse attenuation $(K)$ and the depth limit of colonization (Duarte 1991). However, light levels that ensure the maintenance of SAM abundance or colonization depth limits have been difficult to establish using low frequency (weekly to monthly) observations.

Among SAM species investigated, seagrasses do not penetrate deeper than the mean isolume corresponding to $10 \%$ of the in-water surface irradiance $\left(I_{0}\right)$, but this correlation lacks resolving power on depth scales shorter than about $10 \mathrm{~m}$. Furthermore, different species appear to have different minimum light requirements (Batiuk et al. 1993), and persistence of some species requires mean isolumes greater than $30 \%$ of $I_{0}$ (Onuf 1991, Dennison et al. 1993, Dunton \& Tomasko 1994). In addition, different mean light requirements have been reported for the same species growing in different habitats (Ostenfeld 1908, Borum 1983, Dennison 1987, 1991, Kenworthy et al. 1991), and the apparent light requirement of a single species growing within a single estuary appears to increase as the variance in light availability increases (Zimmerman et al. 1991). Thus, the correlation between mean light attenuation and maximum colonization depth appears to require extensive site- and population-specific calibration in order to generate a useful predictor of environmental suitability.

Transparency of estuarine water columns can be highly variable in time and space (Lüning \& Dring 1979, Cloern 1987, Stross \& Sokol 1989, Carter \& Rybicki 1990, McMahon et al. 1992, Valiela et al. 1992, Pinckney \& Zingmark 1993), and brief periods of extreme attenuation, rather than the mean condition, may be the principal determinant of SAM survival and depth distribution (Zimmerman et al. 1991, Gaines \& Denny 1993, Dring \& Lüning 1994). Proper evaluation of the effects of extreme attenuation events on SAM populations requires a more mechanistic approach than permitted by simple correlation of colonization depth with mean values of $K$ taken at low frequencies. A first step toward an increased mechanistic understanding can be achieved by calculation of daily carbon budgets based on measured rates of instantaneous I, photosynthesis, respiration and growth (Dennison \& Alberte 1982, Wetzel \& Neckles 1986, Zimmerman et al. 1989, Fourqurean \& Zieman 1991, Kraemer \& Alberte 1993)

Fundamental to all carbon budget models, regardless of their structural complexity, is the calculation of production by an appropriately scaled ecosystem 'big leaf' or canopy (Rastetter et al. 1992) from some measure of $I$. The relationship between growth (or production) and the daily integral of light intercepted by the leaf canopy can be linear (Charles-Edwards et al. 1986), but light absorption by the leaf canopy is seldom measured in aquatic systems. Incident $I$ is measured more commonly, but its relation to production, both daily and instantaneous, is strongly non-linear (Blackman 1905). If the daily pattern of $I$ is sinusoidal, the daily production integral can be estimated from a quasi-analytical (non-iterative) polynomial and a single daily measure of the maximum irradiance at solar noon $\left(I_{\mathrm{m}}\right)$ (Thornley \& Johnson 1990, McBride 1992). However, large errors in the daily production estimate can be introduced when the daily in situ pattern of $I$ deviates from sinusoidal.

The daily production integral also can be calculated by numerical integration, i.e. the iterative summation of instantaneous photosynthesis vs irradiance ( $P$ vs $I$ ) throughout the day. Although numerical (iterative) integration is unaffected by non-sinusoidal variations in $I$ it requires essentially continuous measurement of I throughout each day. In sinusoidal light environments, the analytical (non-iterative) and numerical (iterative) methods will produce identical estimates of daily production. The extent to which these integrals differ provides a quantitative evaluation of the potential error introduced into a production model by the use of only $I_{\mathrm{m}}$ and the assumption that $I$ follows a daily sinusoidal trajectory.

The non-linear relationship between $P$ and $I$ is also the basis for the computationally simple $H_{\text {sat }}$ (the daily period of $I$-saturated photosynthesis) model (Evans 1972, Dennison \& Alberte 1982, 1985). In this approach, daily carbon gain is calculated as the product of $P_{m}$ (the maximum rate of irradiance-saturated photosynthesis) and the total time that $I$ exceeds the irradiance required to saturate photosynthesis $\left(I_{k}\right)$. The attractive feature of this model is that time, rather than $I$, is integrated to produce a numerical index $\left(H_{\text {sat }}\right)$ that is related linearly to daily production. $H_{\text {sat }}$ can be calculated directly (non-iteratively) from $I_{m}$ if the daily pattern of $I$ is sinusoidal (Zimmerman et al. 1987), or integrated numerically (iteratively) if continuous measures of $I$ are available. The $H_{\text {sat }}$ model assumes $P=0$ when $I<I_{k}$, whether integrated analytically from $I_{\mathrm{m}}$ or numerically from successive measures of $I$. Theoretically, this can lead to underestimation of daily carbon gain (Richardson et al. 1983, Fourqurean \& Zieman 1991, Henley 1993).

Although carbon budget calculations often assume the daily pattern of $I$ to be sinusoidal (e.g. Kremer \& Nixon 1978, Dennison \& Alberte 1985, Zimmerman et al. 1987, Fourqurean \& Zieman 1991), the effect of nonsinusoidal variations on carbon budget calculations have not been evaluated with real time-series observa- 
tions of $I$. In this study, a continuous record of $I$ from an eelgrass bed located in a central California, USA, estuary was used to compare the ability of analytical (sinusoidal light environment assumed) and numerical (no assumption about temporal light distribution) procedures to predict rates of daily carbon gain using simple models of $P$ vs $I$ for a hypothetical 'big leaf'. The goals of this analysis were (1) to evaluate sensitivity of the analytical integration techniques to non-sinusoidal fluctuations in $I$ recorded in situ, (2) to evaluate the $H_{\text {sat }}$ model of daily production relative to models based on instantaneous $P$ vs $I$ and (3) to provide some guidance for the temporal density of irradiance data required for accurate estimation of daily production by SAM in variable light environments.

\section{METHODS}

Photosynthesis vs irradiance models. A highly simplified, 1-compartment model of gross photosynthesis was employed in this analysis. Symbols used for the models, and their definitions, are summarized in Table 1. Losses, e.g. respiration, DOC (dissolved organic carbon) release, and grazing, were ignored because these processes are not directly dependent on the non-sinusoidal variations in instantaneous irradiance (I), which was the focus of this analysis. The model macrophyte was homogeneous in space with respect to the functional $P$ vs $I$ response and in its exposure to $I$, because these complexities are not directly responsive to the non-sinusoidal variations in $I$. Thus, the temporal variation in instantaneous $P$ depended only on measured temporal fluctuations in $I$.

Two commonly used non-linear models, originally proposed by Jassby \& Platt (1976; Eq. 1) and Webb et al. (1974; Eq. 2), were used to describe the basic $P$ vs $I$ relationship:

$$
P=P_{\mathrm{m}} \tanh \left(I / I_{\mathrm{k}}\right)
$$

$$
P=P_{\mathrm{m}}\left[1-\exp \left(-I / I_{\mathrm{k}}\right)\right]
$$

where $P_{\mathrm{n}}$ defines the maximum (or asymptotic) rate of photosynthesis and $I_{k}$ determines the threshold for irradiance-saturation of photosynthesis. Although the mathematical formulation of $P$ vs $I$ can have a significant impact on the daily integral of photosynthesis (McBride 1992), instantaneous values of $P$ produced by the Jassby-Platt (Eq. 1) and Webb et al. (Eq. 2) formulations differ by a maximum of only $4.8 \%$ at the inflection points of the curves (Fig. 1). The value of $I_{k}$ defined by Eq. (1), however, is $33 \%$ higher than the value of $I_{k}$ defined by Eq. (2). Although this difference in $I_{k}$ produces a trivial difference in the estimate of $P$ from a given value of $I$ (McBride 1992), it can have a significant effect when $I_{\mathrm{k}}$ is used as a direct parameter in the daily integration of $P$, as in the $H_{\text {sat }}$ model.

Time series observations of irradiance. Time series of irradiance were recorded using a pair of spherical

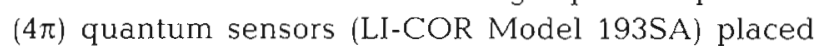
in the Elkhorn Slough National Estuarine Research Reserve, in Monterey Bay, California, during 1991 and 1992. The sensors were deployed in an unvegetated location adjacent to a Zostera marina bed to avoid shading by the leaf canopy. One sensor was placed at the sediment surface, while the other was located $0.5 \mathrm{~m}$ above the first at a height equivalent to the top of the leaf canopy. The upper sensor was covered by at least $0.5 \mathrm{~m}$ of water at all times. The irradiance ( $\mu$ mol quanta $\mathrm{m}^{-2} \mathrm{~s}^{-1}$ ) was recorded from both sensors at 15 min intervals and stored in a LI-COR Model 1000 data logger. Diffuse attenuation coefficients $(K)$ were calculated according to Beer's Law using recorded differences in $I$ between the 2 sensors only from 10:00 and 14:00 h each day to minimize any upward bias in $K$ caused by low sun angles (McPherson \& Miller 1993). The sensors were cleaned by SCUBA divers and the data logger was cycled every $14 \mathrm{~d}$. Accumulation of small amounts of fouling between

\begin{tabular}{|c|c|c|}
\hline Symbol & Definition & Units \\
\hline$I$ & Instantaneous irradiance, PAR & $\mu m o l$ quanta $m^{-2} s^{-1}$ \\
\hline$I_{\mathrm{m}}$ & Maximum daily irradiance (in water) at solar noon & umol quanta $\mathrm{m}^{-2} \mathrm{~s}^{-1}$ \\
\hline$I_{\mathrm{k}}$ & Light-saturation threshold for photosynthesis & umol quanta $\mathrm{m}^{-2} \mathrm{~s}^{-1}$ \\
\hline$P$ & Light-dependent rate of photosynthesis & $\mu \mathrm{mol} \mathrm{C \textrm {g } ^ { - 1 }} \mathrm{FW} \mathrm{min}^{-1}$ \\
\hline$P_{\mathrm{m}}$ & $\begin{array}{l}\text { Maximum, light-saturated rate } \\
\text { of photosynthesis, normalized to biomass }\end{array}$ & $\mu \mathrm{mol} \mathrm{C} \mathrm{g}{ }^{-1} \mathrm{FW} \mathrm{min}^{-1}$ \\
\hline$D$ & Daylength or photoperiod & $\mathrm{h}$ \\
\hline$H_{\text {sal }}$ & Daily period of irradiance-saturated photosynthesis & h \\
\hline K & Coefficient of diffuse attenuation, from Beer's Law & $m^{-1}$ \\
\hline
\end{tabular}

Table 1. Symbols, definitions and units used for model parameters 


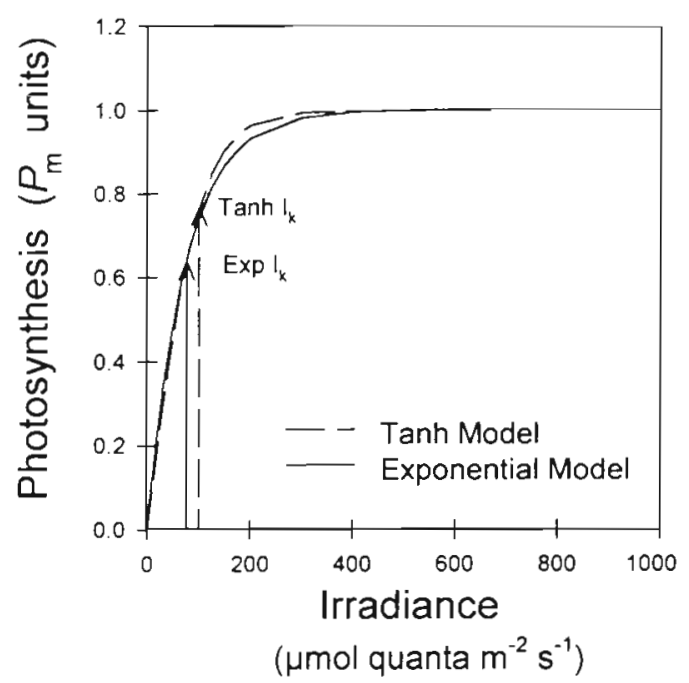

Fig. 1. Hypothetical photosynthesis vs irradiance ( $P$ vs $I$ ) curve demonstrating the ability of the tanh and exponential (exp) models to predict values of $P$ from given values of $I$. Although the curves follow similar trajectories, the value of $I_{\mathrm{k}}$ (irradiance required to 'saturate' $P$ ) generated from the tanh model is $33 \%$ higher than $I_{k}$ derived from the exponential model

cleanings had no measurable effect on recorded values during the $14 \mathrm{~d}$ periods, as evaluated by the difference in $I$ immediately before and after cleaning

Estimates of daily photosynthesis. Daily production values calculated by numerical integration (the iterative summation of $P$ vs $I$ ) are virtually identical for Eqs. (1) \& (2). Therefore estimates of daily production generated by numerical (iterative) integration of Eq. (1) from the complete irradiance time series recorded by the upper sensor were used as a benchmark against which the other integration models were

Table 2. Monthly values of photosynthesis vs irradiance ( $P$ vs $I$ ) parameters used to drive daily production from $I$. $P_{m}$ : maximum rate of light-saturated photosynthesis ( $\mu \mathrm{mol} \mathrm{C}$ $\mathrm{g}^{-1}$ FW $\mathrm{min}^{-1}$ ); $I_{\mathrm{k}}$ : light-saturation threshold for photosynthesis ( $\mu \mathrm{mol}$ quanta $\mathrm{m}^{-2} \mathrm{~s}^{-1}$ )

\begin{tabular}{|lccc|}
\hline Month & $p_{\mathrm{n}}$ & Tanh $I_{\mathrm{k}}$ & Exp $I_{\mathrm{k}}$ \\
\hline August 1991 & 0.69 & 317 & 238 \\
September & 0.55 & 128 & 96 \\
October & 0.88 & 115 & 86 \\
November & 0.72 & 119 & 89 \\
December & 0.77 & 128 & 96 \\
January 1992 & 1.05 & 77 & 58 \\
February & 1.22 & 106 & 80 \\
March & 1.02 & 123 & 92 \\
April & 0.53 & 82 & 62 \\
May & 0.48 & 77 & 58 \\
June & 0.45 & 84 & 63 \\
July & 0.41 & 84 & 63 \\
August & 0.49 & 100 & 75 \\
\hline
\end{tabular}

evaluated. Parameter values $\left(P_{\mathrm{m}}\right.$ and $I_{\mathrm{k}}$ ) were scaled monthly to observed $P$ vs $I$ responses from eelgrass shoots collected in Elkhorn Slough (Table 2).

The relationship between daily production and daily integrated $I$ was determined from numerical integrations of $P$ vs $I$ calculated from Eq. (1) and daily integrated $I$, both calculated from the time series of instantaneous $I$ (upper sensor) measured at $15 \mathrm{~min}$ intervals each day. The relationship was evaluated statistically using the non-linear, direct-fit routine from the NONLIN package of SYSTAT (Wilkinson 1990).

Temporal predictability of daily production was determined from the time required for successive daily estimates to become statistically uncorrelated. Productmoment correlation coefficients $(r)$ for the time series of daily $P$ were calculated for 10 sets of data consisting of 10 successive days of observations using lags of 1 to $4 \mathrm{~d}$.

Quasi-analytical (non-iterative) approximation of the time-integral of Eq. (1) was calculated assuming $I$ to be a sinusoidal function of time $(t)$ since sunrise:

$$
I=I_{\mathrm{m}} \sin \left(\pi \frac{t}{D}\right)
$$

where $I_{\mathrm{m}}$ is the value of $I$ (in water) recorded at solar noon and $D$ is daylength. Substituting for $I$ in Eq. (1), $P$ was redefined as a function of time $(t)$ :

$$
P=P_{\mathrm{m}} \tanh \left[\frac{I_{\mathrm{m}}}{I_{\mathrm{k}}} \sin \left(\frac{\pi t}{D}\right)\right]
$$

The daily integral of $P$ was then approximated by polynomial expansion because direct analytical integration of Eq. (4) is impossible:

$$
\begin{aligned}
\int_{t=0}^{D} P \mathrm{~d} t=P_{\mathrm{m}} D[ & -0.0038+0.71\left(\frac{I_{\mathrm{m}}}{I_{\mathrm{k}}}\right)-0.20\left(\frac{I_{\mathrm{m}}}{I_{\mathrm{k}}}\right)^{2} \\
& +0.0060\left(\frac{I_{\mathrm{m}}}{I_{\mathrm{k}}}\right)^{3}+0.0085\left(\frac{I_{\mathrm{m}}}{I_{\mathrm{k}}}\right)^{4} \\
& -0.0019\left(\frac{I_{\mathrm{m}}}{I_{\mathrm{k}}}\right)^{5}+1.8 \times 10^{-4}\left(\frac{I_{\mathrm{m}}}{I_{\mathrm{k}}}\right)^{6} \\
& \left.-8.2 \times 10^{-6}\left(\frac{I_{\mathrm{m}}}{I_{\mathrm{k}}}\right)^{7}+1.4 \times 10^{-7}\left(\frac{I_{\mathrm{m}}}{I_{\mathrm{k}}}\right)^{8}\right]
\end{aligned}
$$

This relation was valid over the domain $0 \leq\left(I_{\mathrm{m}} / I_{\mathrm{k}}\right) \leq 20$, spanning a range of conditions from total darkness to extremely bright sunlight where $I_{\mathrm{m}}=20 I_{\mathrm{k}}$ that should encompass most light environments experienced by SAM le.g. if $I_{m}=2000 \mu \mathrm{mol}$ quanta $\mathrm{m}^{-2} \mathrm{~s}^{-1}, I_{\mathrm{k}}=$ $100 \mu \mathrm{mol}$ quanta $\mathrm{m}^{-2} \mathrm{~s}^{-1}$ ). Daylength $(D)$ was adjusted daily assuming a sinusoidal function with a mean of $12 \mathrm{~h}$ ( $D=12 \mathrm{~h}$ on the vernal and autumnal equinoxes) and an amplitude of $2 \mathrm{~h}(D=14 \mathrm{~h}$ on the summer solstice, $10 \mathrm{~h}$ on the winter solstice): 


$$
D=12-2 \cos \left(2 \pi \frac{\text { Julian Date }+10}{365}\right)
$$

Analytical values of $H_{\text {stt }}$ were calculated for each day according to:

$$
H_{\text {sat }}=D\left[1-\frac{2}{\pi} \sin ^{-1}\left(\frac{I_{\mathrm{k}}}{I_{\mathrm{m}}}\right)\right]
$$

Like Eq. (5), this relationship assumed $I$ to be a sinusoidal function of time since sunrise (Fig. 2). Thus, $\sin ^{-1}\left(I_{k} / I_{m}\right)$ defines the fraction of the day (in radians) between sunrise (or sunset) and the time when $I=I_{\mathrm{k}}$. Since $I$ varies sinusoidally, multiplication of $\left[\sin ^{-1}\left(I_{\mathrm{k}} / I_{\mathrm{m}}\right)\right]$ by $2 / \pi$ provides the total portion of the day when $I<I_{\mathrm{k}}$. Subtraction from 1 converts the proportion to $H_{\text {sal }}$ (unscaled). Multiplication by $D$ scales $H_{\text {sat }}$ to daylength. The value of $I$ recorded at solar noon each day was used as $I_{\mathrm{m}}$. As with the polynomial integration of $P$ vs $I$ (Eq. 5), $H_{\text {sat }}$ estimates were determined from single daily records of $I_{\mathrm{m}}$ and daily adjustments of $D$ (Eq. 6). Daily values of $H_{\text {sat }}$ were also integrated numerically for the recorded time series of $I$ by summing the 15 min time intervals in which $I$ exceeded $I_{\mathrm{k}}$ each day, analogous to the numerical integration of $P$ vs $I$. Daily production estimates were then calculated as $P_{\mathrm{m}} H_{\text {sat }}$ for both the numerical and analytical integration of $H_{\text {sat. }}$. The $H_{\text {sat }}$ model assumes $P=0$ during periods when $I<I_{k}$, and therefore should underestimate daily production.

\section{RESULTS}

\section{Time series observations of irradiance}

The day-to-day variation in integrated submarine irradiance was so great at the depth of the eelgrass canopy in Elkhorn Slough that no obvious seasonal pattern was observed (Fig. 3a), even though there are predictable seasonal amplitudes in daylength of $2 \mathrm{~h}$ and in maximum incident $I$ (in air) of almost $1000 \mu \mathrm{mol}$ quanta $\mathrm{m}^{-2} \mathrm{~s}^{-1}$ at this latitude. Periodic events of extremely high $K$ (low $I$ ) persisted from 1 to $10 \mathrm{~d}$. The longest of these events was caused by water column turbidity associated with a rainy period in February and March 1992. Other extreme attenuation events of short duration ( 1 to $2 \mathrm{~d}$ ) were generally associated with sediment loading and resuspension from storms and spring tides.

The mean $K$ measured between 10:00 and 14:00 h showed a high degree of day-to-day variability (Fig. 3b). Although there was no clear seasonal pattern in mean $K$, there was some suggestion of a seasonal pattern in the variance component. The attenuation coefficient was most variable from December to March, which

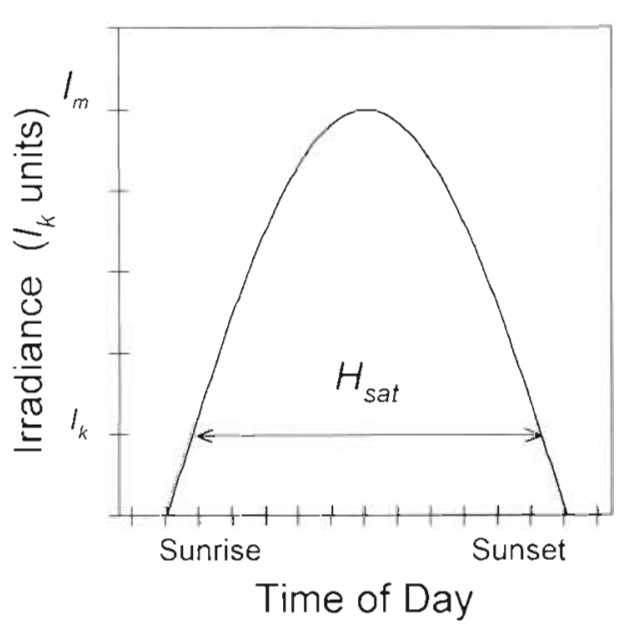

Fig. 2. Diagrammatic representation of $H_{\text {sat }}$ (daily period of I-saturated photosynthesis), as defined for a cloudless day. On cloudless days, $H_{\text {sat }}$ can be estimated from knowledge of daylength $(D)$ and maximum noon irradiance $\left(I_{m}\right)$. According to this definition, $P=0$ when $I<I_{\mathrm{k}}$

corresponds to the rainy season in central California. During this period, winter rains were responsible for episodic runoff which greatly increased the load of suspended particles in the water column of Elkhorn Slough. In addition, the spring low tides that also resuspend sediments occur during the afternoons in winter, complicating the temporal pattern of variation in $K$

In sinusoidal light environments, the daily timeintegral of $I$ (Eq. 3) is a linear function of $I_{\mathrm{m}}$ and daylength $(D)$ :

$$
\int_{t=0}^{D} I \mathrm{~d} t=\int_{t=0}^{D} I_{\mathrm{m}} \sin \left(\frac{\pi t}{D}\right) \mathrm{d} t=\frac{2}{\pi}\left(I_{\mathrm{m}} D\right)
$$

This relationship also permits calculation of the upper and lower limits of the daily light integral to be expected from seasonal changes in $D$ over any range of $I_{\mathrm{m}}$. In sinusoidal light environments, the daily light integral will be constrained by the seasonal amplitude in $D$, which ranges from 10 to $14 \mathrm{~h}$ at the latitude of Elkhorn Slough. Measured values of $\int I$ outside these bounds can result from non-sinusoidal variations in $I$, particularly around noon, that might affect the determination of $I_{\mathrm{m}}$. The correlation between the light integral and $I_{\mathrm{m}}$ (in water) measured in Elkhorn Slough was statistically significant $(\mathrm{r}=0.76, \mathrm{n}=171, \mathrm{p}<0.01)$, but $I_{\mathrm{m}}$ was not a quantitatively reliable predictor of the daily light integral (Fig. 4). Fully $42 \%$ of the variation in the light integral remained unexplained after linear regression against $I_{\mathrm{m}}\left(\mathrm{r}^{2}=0.58\right)$. Furthermore, $73 \%$ of the measured daily integrals fell outside the theoretical boundaries set by the lower and upper limits of $D(10$ and $14 \mathrm{~h}$, respectively) indicating that observed noon irradiances (assumed to be $I_{\mathrm{m}}$ ) were not reliable pre- 


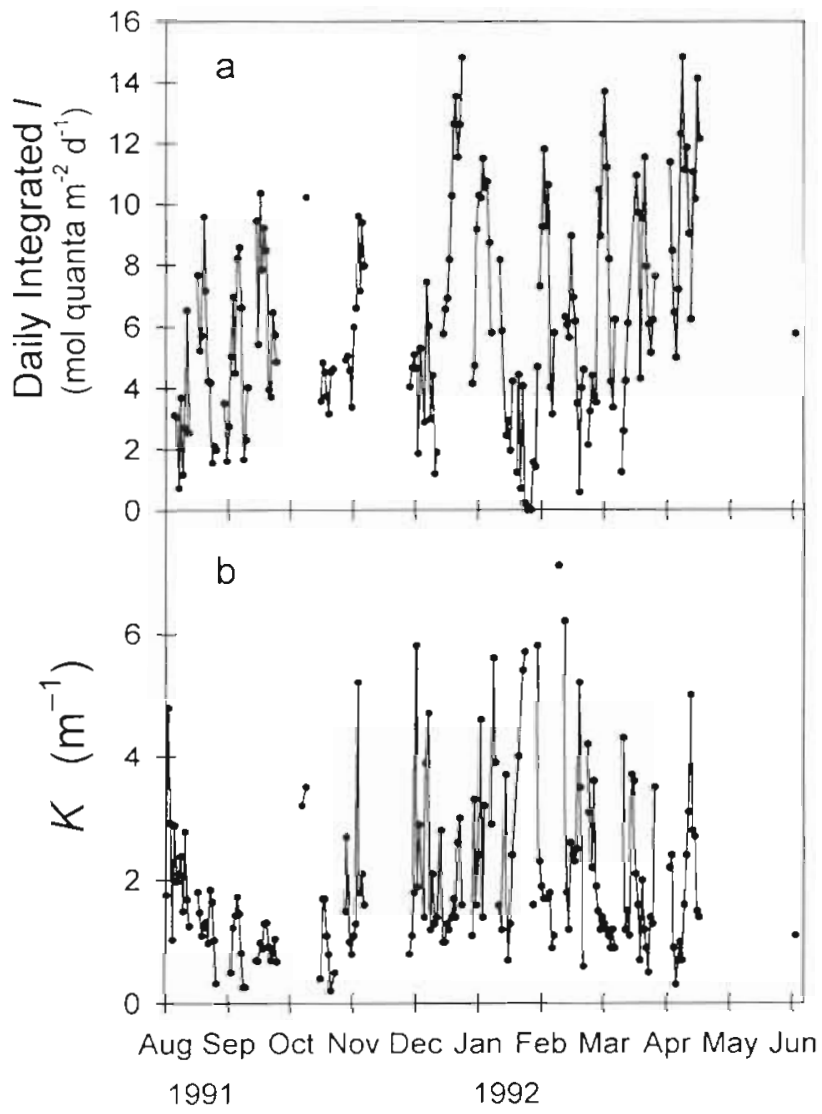

Fig. 3. (a) Time series of daily integrated irradiance at the Elkhorn Slough study site. Although there was a high degree of variation in daily irradiance (I), no seasonal pattern was evident from these data. (b) Time series of diffuse attenuation coefficient $(K)$. Day-to-day variations were most dramatic during the winter (December to March) rainy season

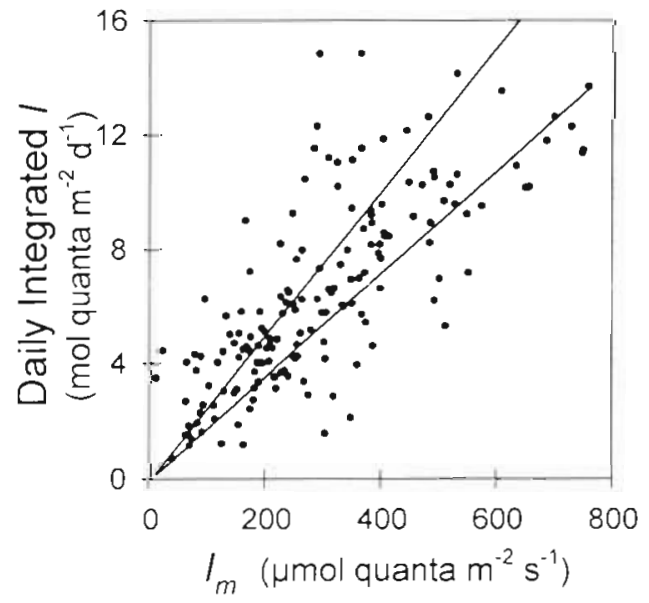

Fig. 4. Daily integrated irradiance (I) plotted as a function of the instantaneous $I$ (in water) irradiance (upper sensor) at solar noon $\left(I_{\mathrm{m}}\right)$. Lines represent the upper and lower bounds for the light integral predicted from sinusoidal theory for daylengths of 14 and $10 \mathrm{~h}$, respectively dictors of daily integrated $I$. Thus, the daily integral of light availability in Elkhorn Slough was not well approximated by sinusoidal theory.

\section{Estimates of daily net production}

The variability in instantaneous $I$ produced a high degree of variability in the time series of daily production calculated by numerical integration of Eq. (1). As with the light data, there was no obvious seasonal pattern (Fig. Sa). In addition, there was virtually no correlation between sequential estimates of daily production (Fig. 5 b). The correlation ( $\mathrm{r}$ ) of daily production on any given day with the estimate from the following day was statistically insignificant $(r=0.48, n=10, p>0.05)$ for 10 sets of 10 successive days of observations. Thus it was impossible to estimate daily production from any given observation even $1 \mathrm{~d}$ into the future. Correla-

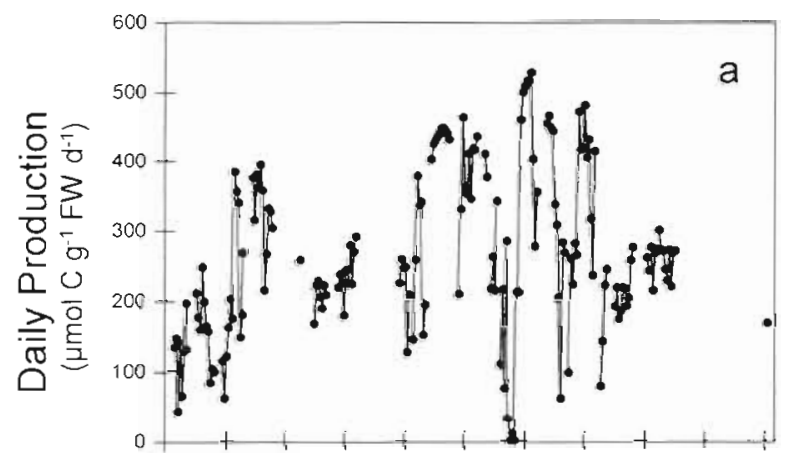

Aug Sep Oct Nov Dec Jan Feb Mar Apr May Jun 1991 1992

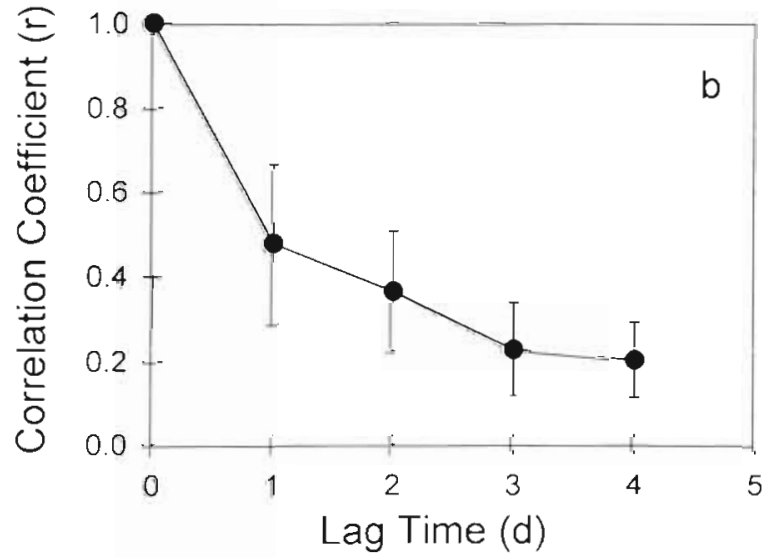

Fig. 5. (a) Time series of daily production calculated from numerical integration of the tanh $P$ vs $I$ model, using continuous recording of irradiance. (b) Correlation coefficient plotted as a function of lag period (d) for 10 sets of 10 sequential days of numerically integrated production data. Error bars indicate $95 \%$ confidence limits of the mean for each lag. With $\mathrm{n}=10, \mathrm{r}$ must exceed 0.58 to be statistically significant at $\mathrm{p}=0.05$ 
tions of production estimates separated by more than $1 \mathrm{~d}$ were even lower. Clearly, this lack of correlation in successive daily production estimates was caused by the high degree of day-to-day variability in the temporal distribution of $I$, both within and between days.

The relationship between numerically integrated production and numerically integrated daily $I$ showed a non-linearity reminiscent of the instantaneous $P$ vs $I$ response, and could be described by Eqs. (1) or (2), the same formulations as the instantaneous $P$ vs $I$ response curve (Fig. 6). Even though all of the irradiance timeseries data were used in summing both daily $P$ and the daily integral of $I$, the predictive reliability of this model was poor $\left(\mathrm{r}^{2}=0.53\right)$, especially when the daily integral of $I$ exceeded 4 mol quanta $\mathrm{m}^{-2} \mathrm{~d}^{-1}$.

Polynomial integration of $P$ (Eq. 5), based on a single daily measure of $I_{\mathrm{m}}$, was not a reliable predictor of the numerical integration of $P$ vs $I$ (Fig. 7, Table 3). In addition to the high residual uncertainty $\left(r^{2}=0.71\right)$, daily production estimates were upwardly biased by an average of $59 \mu \mathrm{mol} \mathrm{C} \mathrm{g}^{-1} \mathrm{FW} \mathrm{d}^{-1}$, relative to the numerical integration of Eq. (1).

As with the polynomial integral, estimating daily $P$ by analytical integration of $H_{\text {sat }}$ (Eq. 7) from single daily measurements of $I_{\mathrm{m}}$ proved to be inaccurate, regardless of the formulation of $I_{k}$ (Fig. 8, Table 3). The $H_{\text {sat }}$ period was 0 on $30(18 \%$ of the time) and $19(11 \%$ of the time) occasions using values of $I_{\mathrm{k}}$ calculated from the tanh and exponential formulations of $P_{\mathrm{Vs}} I_{\text {i }}$ respectively. The high degree of scatter in the $H_{\text {sat }}$ estimates of daily $P$ obscured the presence of systematic biases

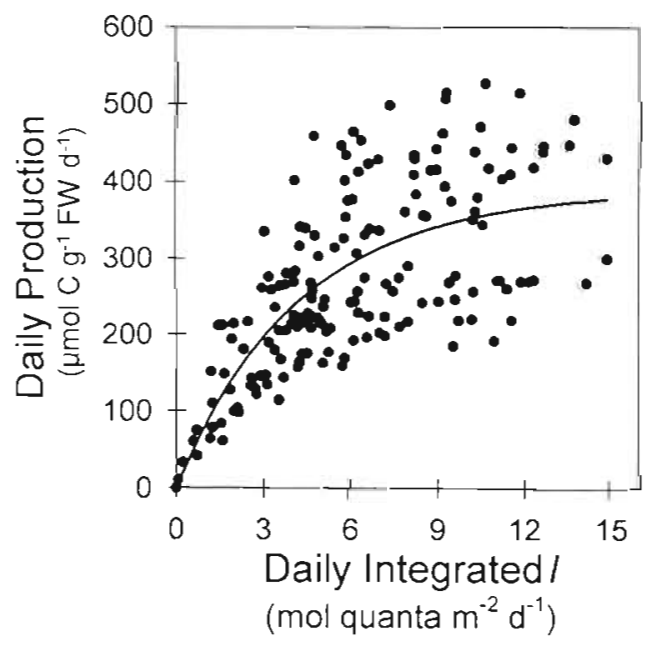

Fig. 6. Numerically integrated daily production plotted as a function of integrated daily irradiance $(I)$. The line represents a direct least-squares fit of $\int P$ to $\int I$ using the exponential $P$ vs $I$ model of Webb et al. (1974). The high degree of scatter makes any mathematical relationship between $j P$ and $\int I$ unreliable for predicting daily production, especially when $I I$ exceeded 4 mol quanta $\mathrm{m}^{-2} \mathrm{~d}^{-1}$

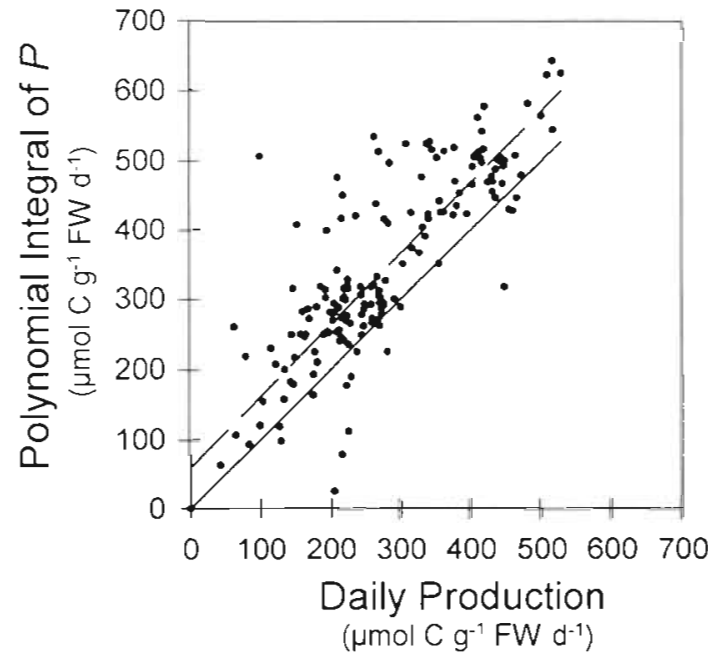

Fig. 7. Polynomial integration of daily production plotted as a function of daily production calculated by the numerical integration of $P$ vs $I$. Solid line: perfect agreement between the 2 measures (slope $=1$, intercept $=0$ ), dashed line: linear regression results. Regression statistics can be found in Table 3

in the relationships, but residual errors were sufficiently large to preclude the practical application of single measurements of $I_{\mathrm{m}}$ for the calculation of $H_{\mathrm{sat}}$ values and daily production rates regardless of the $P$ vs $I$ formulation used to calculate $I_{\mathrm{k}}$ (Table 3 ).

In contrast to the analytical (non-iterative) integrals of $P$ vs $I$ and $H_{\text {sat }}$, numerical (iterative) integrations of $H_{\text {sat }}$ were reasonable predictors of daily production (Table 3). When $H_{\text {sal }}$ was based on the tanh calculation of $I_{\mathrm{k}}$ (Eq. 1), the regression slope was essentially 1 , but the negative intercept indicated a downward bias (underestimate) of $40 \mu \mathrm{mol} \mathrm{C} \mathrm{g}^{-1} \mathrm{FW} \mathrm{d}^{-1}$ in the calculation of daily $P$ (Fig. $9 \mathrm{a}$, Table 3). Daily $P$ was estimated to be zero on 8 ( $5 \%$ of the time) of the 171 days when $I$ did not rise above $I_{k}$, hence $H_{\text {sat }}$ was undefined.

Agreement between the numerically integrated $H_{\text {sat }}$ calculation of daily $P$ and the numerical integration of $P$ vs $I$ increased when $H_{\text {sat }}$ was based on the exponential calculation of $I_{\mathrm{k}}$ (Eq. 2; Fig. 9b). As with the tanh formulation, the regression slope was not significantly different from 1 . There was a slight improvement in the overall correlation $\left(\mathrm{r}^{2}=0.94\right)$, and a considerable upward shift in the $y$-intercept such that the underestimate of daily production was reduced by $58 \%$ (Table 3). The value of $H_{\text {sat }}$ was undefined on only $6(4 \%$ of the time) of the 171 days included in the analysis.

Although analytical estimates based on single daily observations of $I_{\mathrm{m}}$ were not reliable predictors of daily $P$ in Elkhorn Slough, the $H_{\text {sat }}$-based estimates showed remarkable agreement with estimates calculated by the polynomial integral (Fig. 10, Table 3). Serious disagreement between the analytical $H_{\text {sat }}$ and polynomial 
Table 3. Regression parameters from comparisons of production estimates plotted as dashed lines in Figs. 7 to 10. Variables are listed as independent (ordinate) and dependent (abscissa) based on their orientation in Figs. 7 to 10. Standard errors of slopes and intercepts are listed in parentheses

\begin{tabular}{|c|c|c|c|c|c|}
\hline Independent variable & Dependent variable & Slope & Intercept & $r^{2}$ & df \\
\hline \multicolumn{6}{|l|}{ Numerical integral of $P$} \\
\hline Fig. 7 & Polynomial integral of $P$ & $1.03(0.05)$ & $59(78)$ & 0.71 & 169 \\
\hline & Analytical integral of $H_{\text {sat }}$ & & & & \\
\hline Fig. $8 a$ & Tanh model & $1.09(0.07)$ & $-13(108)$ & 0.59 & 169 \\
\hline Fig. $8 b$ & Exponential model & $1.11(0.06)$ & 19 (99) & 0.64 & 169 \\
\hline & Numerical integral of $H_{\text {sat }}$ & & & & \\
\hline Fig. 9a & Tanh model & $0.97(0.02)$ & $-40(36)$ & 0.92 & 169 \\
\hline Fig. $9 b$ & Exponential model & $1.00(0.02)$ & $-17(30)$ & 0.94 & 169 \\
\hline Polynomial integral of $P$ & Analytical integral of $H_{\text {sat }}$ & & & & \\
\hline Fig. 10a & Tanh model (all data) & $1.09(0.03)$ & $-83(60)$ & 0.87 & 169 \\
\hline Line not plotted & Only data $>200 \mu \mathrm{mol} \mathrm{C} \mathrm{g}^{-1} \mathrm{FW} \mathrm{d}^{-1}$ & $0.98(0.01)$ & $-28(21)$ & 0.96 & 131 \\
\hline Fig. $10 \mathrm{~b}$ & Exponential model (all data) & $1.09(0.02)$ & $-48(45)$ & 0.92 & 169 \\
\hline Line not plotted & Only data $>200 \mu \mathrm{mol} \mathrm{C} \mathrm{g}^{-1} \mathrm{FW} \mathrm{d}^{-1}$ & $0.99(0.004)$ & $-3(6)$ & 0.997 & 141 \\
\hline
\end{tabular}

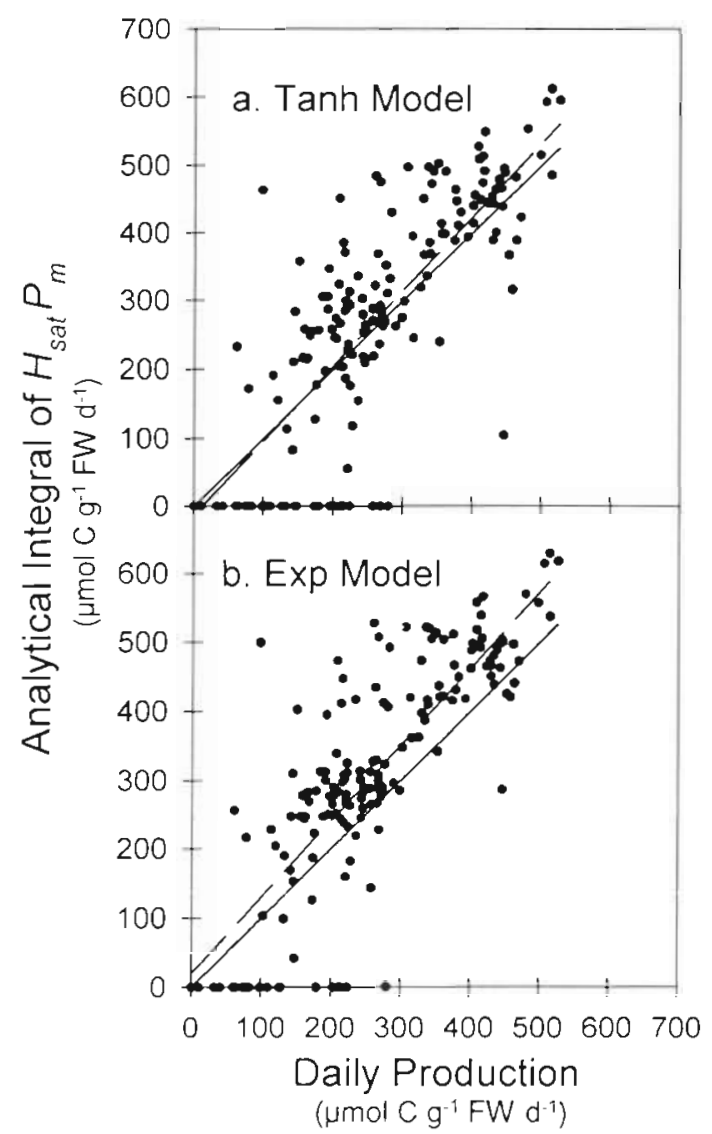

Fig. 8. Daily production estimated from analytical approximation of (a) $H_{\text {sat }}$ (tanh model) and (b) $H_{\text {sat }}$ (exponential model) plotted as a function of daily production calculated by the numerical integration of $P$ vs $I$. Solid lines: perfect agreement between the plotted measures (slope $=1$, intercept $=0$ ); dashed lines: linear regression results. Regression statistics can be found in Table 3

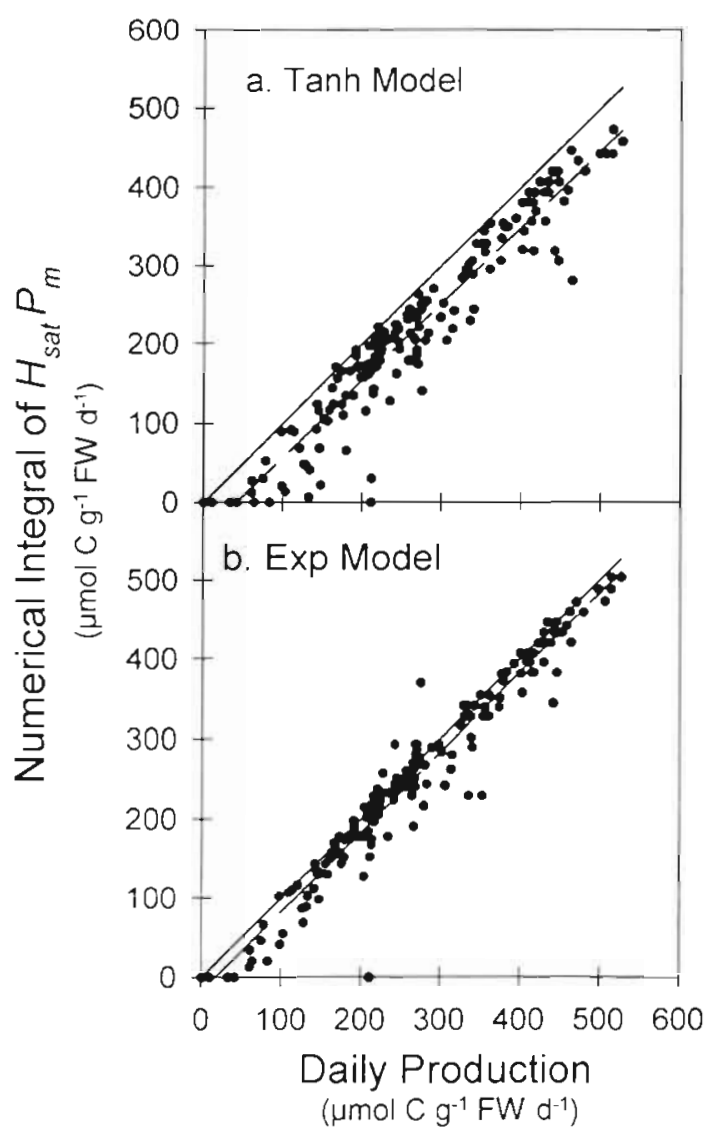

Fig. 9. Daily production calculated from numerical integration of (a) $H_{\text {sat }}$ (tanh model) and (b) $H_{\text {sat }}$ (exponential model) plotted as a function of daily production calculated by the numerical integration of $P$ vs $l$. Solid lines: perfect agreement between the plotted measures (slope $=1$, intercept $=0)_{\text {i }}$ dashed lines: linear regression results. Regression statistics can be found in Table 3 


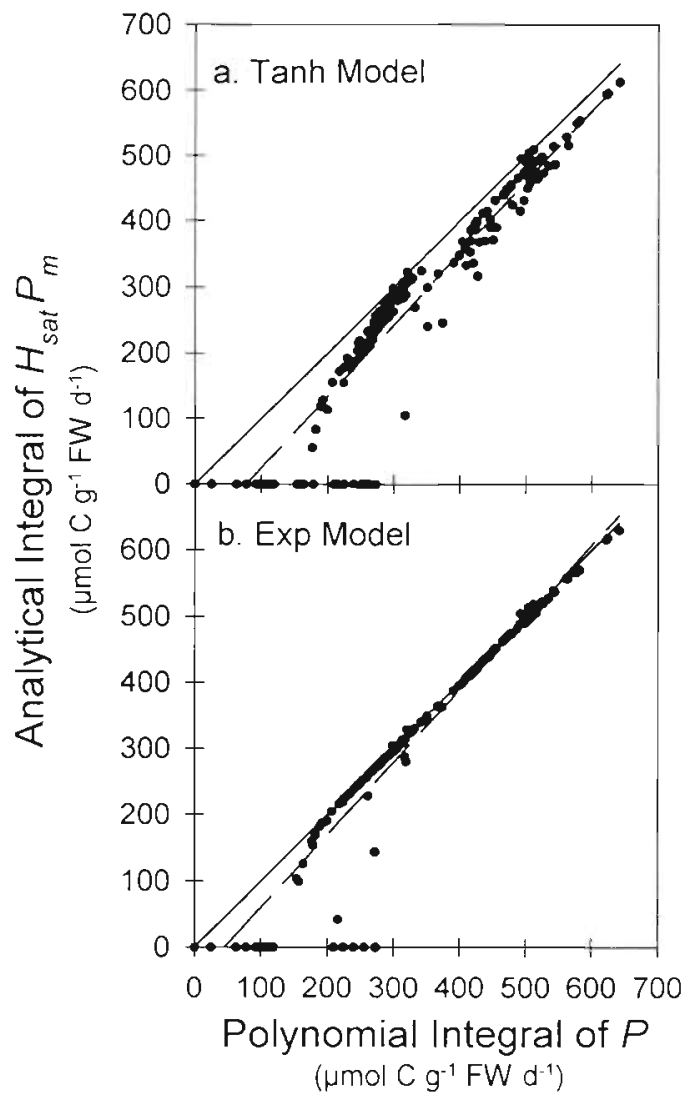

Fig. 10. Daily production estimated from analytical approximation of (a) $H_{\text {sal }}$ (tanh model) and (b) $H_{\text {sal }}$ (exponential model) plotted as a function of the polynomial integral of photosynthesis $(P)$. Solid lines: perfect agreement between the plotted measures (slope $=1$, intercept $=0$ ); dashed lines: linear regression results. Regression statistics can be found in Table 3

integral occurred only on days when $I_{\mathrm{m}}$ remained near $I_{\mathrm{k}}$ and $H_{\mathrm{sat}}$ approached 0 . The high value of $I_{\mathrm{k}}$ produced from the tanh formulation (Eq. 1) caused $H_{\text {sat }}$ to consistently underestimate daily $P$ and to show less agreement with the polynomial integral in comparison to the integral of $H_{\text {sat }}$ determined from the estimate of $I_{\mathrm{k}}$ derived from Eq. (2) (Fig. 10a). Agreement between the polynomial integral of $P$ and the analytical integral of $H_{\mathrm{sat}} P_{\mathrm{m}}$ based on the exponential formulation of $I_{\mathrm{k}}$ (Eq. 2), however, was virtually perfect for values of daily $P \geq 200 \mu \mathrm{mol} \mathrm{C} \mathrm{g}{ }^{-1} \mathrm{FW} \mathrm{d}{ }^{-1}$ (Fig. 10b, Table 3). Thus, the exponential formulation of $I_{k}$ may be preferable to the tanh formulation for the application of $H_{\text {sat }}$ to rates of daily production.

\section{DISCUSSION}

Most aquatic light monitoring programs, as currently implemented, focus on the collection of Secchi disk or in situ irradiance data for the calculation of water column attenuation coefficients $(K)$, and stations are visited at infrequent (weekly to monthly) intervals (Batiuk et al. 1993, Dennison et al. 1993, Morris \& Virnstein 1993). In addition, extreme turbidity events are often left unsampled, since the storms and high winds that generate them often prevent manual sampling. The high-frequency variations in light attenuation observed in Elkhorn Slough probably are typical of coastal environments where water column turbidity is affected by physical and biotic factors operating on a variety of time scales. This notion is supported by the occurrence of processes such as wind and tidal mixing, storm runoff and phytoplankton blooms which can combine to produce turbid pulses with chaotic periodicity (Cloern 1987, Stross \& Sokol 1989, Carter \& Rybicki 1990, Zimmerman et al. 1991, McMahon et al. 1992, Valiela et al. 1992, Dring \& Lüning 1994). In this study, the time scale for decorrelation of daily integrated $P$ was on the order of $1 \mathrm{~d}$. Thus, characterization of water transparency or SAM productivity would be impossible if samples were taken at weekly intervals, as has been found for benthic microalgae (Pinckney \& Zingmark 1993).

The diffuse attenuation coefficient $(K)$ calculated from Beer's Law is commonly used to predict habitat suitability for SAM (Lüning \& Dring 1979, Duarte 1991. Batiuk et al. 1993, Dennison et al. 1993). In practice, $K$ is usually assumed to be a 'quasi-inherent' optical property of the water column, enabling the effects of atmospheric scattering and sun angle to be ignored (Kirk 1983). Although this assumption may be valid in optically deep water (Siegel \& Dickey 1987), it is not necessarily true in coastal environments where the optical depth is shallow. In Tampa Bay, Florida, USA, solar angle alone caused $K$ to vary as much as $50 \%$ within a single day (McPherson \& Miller 1993). Thus, time of day becomes a critical component if the goal is to estimate $I$ throughout the water column. Continuous measurements at a minimum of 2 depths will be required to resolve accurately the temporal variation in both incident $I$ and $K$ for many applications. If the goal is to predict SAM production, then continuous data should be collected at the primary depths and sites of interest ${ }_{i}$ extrapolations to other locations and/or depths should be performed with caution.

Numerical integration of $P$ vs I provides the best estimate of daily production, assuming accurate estimates of $I$ can be obtained. The daily integral of $I$ may provide a relative index of light availability, but it could not provide an accurate estimate of daily carbon gain in the case examined here, even though it was also calculated from continuous recordings of $I$. This results from the fundamentally non-linear relationship between $P$ and $I$. 
Polynomial integration of $P$ vs $I$ and analytical integration of $H_{\text {sat }}$, both calculated from single daily observations of $I_{\mathrm{m}}$, were also poor predictors of daily production calculated from the numerical integration of $P$ vs $I$. Even if the daily production integral could be predicted accurately from single daily measures of $I_{\mathrm{m}}$, the time scale for successive daily production estimates to become completely uncorrelated was so short that low frequency (days to weeks) measures of $K$ were clearly inadequate for determining SAM productivity.

Numerical integration of $H_{\text {sat }}$ provided a more reasonable first-order approximation to the numerical integration of $P$ vs $I$. Thus, the $H_{\text {sat }}$ concept can be used to estimate daily production even though the squarewave assumption of the model appears conceptually flawed (Richardson et al. 1983, Fourqurean \& Zieman 1991, Henley 1993). The key to successful application of $H_{\text {sat }}$ clearly is tied to the value of $I_{\mathrm{k}}$. Although operationally defined as the irradiance required to saturate photosynthesis, the mathematical definition of $I_{\mathrm{k}}$ is considerably different and subject to variation based on the formulation of $P$ vs $I$. For example, the tanh function (Eq. 1) defines $P=0.76 P_{\mathrm{m}}$ when $I=I_{\mathrm{k}}$ while $P=$ $0.63 P_{\mathrm{m}}$ with the exponential function (Eq. 2). As a result, the $H_{\text {sat }}$ period (defined as $I>I_{k}$ ) is actually longer than the period when $P=P_{\mathrm{m}}$, based on instantaneous $P$ vs $I$. Furthermore, the length of $H_{\text {sat }}$ is inversely proportional to the value of $I_{k}$. Thus, it may be fortuitous that the exponential formulation (Eq. 2) provided the best value of $I_{\mathrm{k}}$ for numerically integrating $H_{\text {sat }}$ from the highly variable set of irradiance data collected from Elkhorn Slough. However, the almost perfect coherence between the analytical integral of $\left(H_{\text {sat. }} P_{\mathrm{m}}\right)$ defined by Eq. (2) and the polynomial integral of $P$ vs $I$ suggests that the exponential formulation provides the optimum general estimate of $I_{k}$ for determining $H_{\text {sat }}$. Thus, $H_{\text {sat }}$ can be an excellent index of daily production, despite the theoretical flaw in its definition (Richardson et al. 1983, Fourqurean \& Zieman 1991, Henley 1993).

Although the present study was carried out in an extremely turbid estuary ( $K$-values can exceed 6.0 ), $H_{\text {sat }}$ was undefined less than $10 \%$ of the time. Furthermore, careful application of the $H_{\text {sat }}$ model was able to provide very good first approximations to both the numerical and polynomial integration of $P$ vs $I$. Thus, the $H_{\text {sat }}$ model can be applied with confidence to calculations of daily production even in turbid estuaries.

The concept of $H_{\text {sat }}$ also may have significant ecological implications to seagrasses beyond daily production because it directly affects carbon transport and anoxic stress in root tissues anchored in permanently flooded sediments. Aerobic metabolism of root tissues in eelgrass depends directly on photosynthetic $\mathrm{O}_{2}$ production by the leaves (Smith et al. 1984). Eelgrass roots can tolerate prolonged anoxia providing there are ample carbohydrate supplies to support energy production and growth (Smith 1989, Kraemer \& Alberte 1993). Root anoxia, however, blocks sucrose transport from leaves to roots in eelgrass seedlings (Zimmerman \& Alberte unpubl.), as it does in many vascular plant species (Geiger \& Sovonick 1975, Jackson \& Drew 1984, Saglio 1985). Thus, $H_{\text {sat }}$ may provide useful indices of the daily period of root aerobiosis, sucrose transport and carbon partitioning in seagrasses, in addition to daily production. These issues will become more important as growth models develop more mechanistic detail and improved predictive capacity.

It appears that accurate determination of daily carbon budgets for SAM will require continuous records of irradiance. Single daily measures of $I$ were inadequate to estimate daily production with an acceptable degree of precision in this data set. Thus, it is extremely unlikely that measures of $I_{m}$ or $K$ made at weekly or monthly intervals will be of any ecological utility unless the environment is very predictable, in which case they probably could be estimated from first principles as described by Kirk (1983). Coastal seas and estuaries are unlikely places to find such stable conditions and the literature is rich with examples of such highly variable light environments (Lüning \& Dring 1979, Cloern 1987, Stross \& Sokol 1989, Carter \& Rybicki 1990, Zimmerman et al. 1991, McMahon et al. 1992, Valiela et al. 1992, Pinckney \& Zingmark 1993, Dring \& Lüning 1994).

In recognition of the difficulty in measuring light availability, depth distributions of SAM have been proposed as low-technology barometers of estuarine habitat quality (Dennison et al. 1993). However, use of macrophytes as 'miner's canaries' seems inappropriate if the management goal is to reverse losses of SAM by improving water clarity. The model comparisons made here and other investigations (Zimmerman et al. 1991) demonstrate that submarine light availability must be measured with greater temporal and spatial resolution than is generally implemented. This will necessitate the exploitation of recent advances in electronic technology that now enable field sites to be permanently instrumented with continuously recording light monitoring equipment, as it is extremely unlikely that reliance on low-frequency measurement of $I$ or $K$ will generate useful data sets determining daily production of submerged aquatic macrophytes.

Acknowledgements. Many thanks to Susan Britting for assistance with laboratory and field work associated with this project. We are also grateful for the comments and suggestions from Matthew Dring, Ken Dunton, Roger Phillips, Celia Smith and James Watanabe that improved the manuscript. Mark Silberstein (Elkhorn Slough Foundation) and Steven Kimple (Reserve Manager, Elkhorn Slough National Estuar- 
ine Research Reserve) provided logistical support. Financial support was provided by Grant NA17OR252-01 from the National Estuarine Research Reserve Program, National Oceanic and Atmospheric Administration and Grant OCE9223265 from the National Science Foundation.

\section{LITERATURE CITED}

Backman, T W., Barilotti, D. C. (1976). Irradiance reduction: effects on standing crops of the eelgrass Zostera marina in a coastal lagoon. Mar. Biol. 34: 33-40

Batiuk, R. A., Orth, R. J., Moore, K. A., Dennison, W. C., Stevenson, J. C., Staver, L. W., Carter, V., Rybicki, N. B., Hickman, R. E., Kollar, S., Bieber, S., Heasley, P. (1993). Chesapeake Bay submerged aquatic vegetation habitat requirements and restoration targets: a technical synthesis. Chesapeake Bay Program, U.S. Environmental Protection Agency, Annapolis, MD

Blackman, F. F. (1905), Optima and limiting factors. Annls Bot. 19: $218-239$

Borum, J. (1983). The quantitative role of macrophytes, epiphytes, and phytoplankton under different nutrient conditions on Rosskilde Fjord, Denmark. In: Proc. Int. Symp. Aquat. Macrophytes, Nijmegen, p. 35-40

Cambridge, M. L., McComb, A. J. (1984). The loss of seagrasses in Cockburn Sound, Western Australia. I. The time course and magnitude of seagrass decline in relation to industrial development. Aquat. Bot. 20: 229-243

Carter, V., Rybicki, N. B. (1990). Light attenuation and submersed macrophyte distribution in the tidal Potomac River and estuary. Estuaries 13: 441-452

Charles-Edwards, D., Doley, D., Rimmington, G. M. (1986). Modelling plant growth and development. Academic Press, New York

Cloern, J. E. (1987). Turbidity as a control on phytoplankton biomass and productivity in estuaries. Cont. Shelf Res. 7 : $1367-1381$

Dennison, W. C. (1987). Effects of light on seagrass photosynthesis, growth and depth distribution. Aquat. Bot. 27: $15-26$

Dennison, W. C. (1991). Photosynthetic and growth responses of tropical and temperate seagrasses in relation to Secchi depth, light attenuation and daily light period. In: Kenworthy, W. J., Haunerts, D. E. (eds.) Results and recommendations of a workshop convened to examine the capability of water quality criteria, standards and monitoring programs to protect seagrasses from deteriorating water transparency. Final report. South Florida Water Management District, West Palm Beach, p. 133-144

Dennison, W. C., Alberte, R. S. (1982). Photosynthetic response of Zostera marina $\mathrm{L}$. (eelgrass) to in situ manipulations of light intensity. Oecologia 55: 137-144

Dennison, W. C., Alberte, R. S. (1985). Role of daily light period in the depth distribution of Zostera marina (eelgrass). Mar. Ecol. Prog. Ser. 25: 51-61

Dennison, W. C., Alberte, R. S. (1986). Photoadaptation and growth of Zostera marina L. (eelgrass) transplants along a depth gradient. J. exp. mar. Biol. Ecol. 98: 265-282

Dennison, W. C., Orth, R. J., Moore, K. A., Stevenson, J. C., Carter, V., Kollar, S., Bergstrom, P. W., Batiuk, R. A. (1993). Assessing water quality with submersed aquatic vegetation. Habitat requirements as barometers of Chesapeake Bay health. BioSci. 43: 86-94

Dring, M. J., Lüning, K. (1994). Influence of spring-neap tidal cycles on the light available for photosynthesis by benthic marine plants. Mar. Ecol. Prog. Ser. 104: 131-137
Duarte, C. M. (1991). Seagrass depth limits. Aquat. Bot. 40: $363-377$

Dunton, K. H., Tomasko, D. A. (1994). In situ photosynthesis in the seagrass Halodule wrightii in a hypersaline subtropical lagoon. Mar. Ecol. Prog. Ser. 107: 281-293

Evans, G. C. (1972). The quantitative analysis of plant growth. University of California Press, Berkeley

Fourqurean, J. W., Zieman, J. C. (1991). Photosynthesis, respiration and whole plant carbon budget of the seagrass Thalassia testudinum. Mar. Ecol. Prog. Ser. 69: $161-170$

Gaines, S. D., Denny, M. W. (1993). The largest, smallest, highest, lowest, longest and shortest: extremes in ecology. Ecology 74: 1677-1792

Geiger, D. R., Sovonick, S. A. (1975). Effects of temperature, anoxia and metabolic inhibitors on translocation. In: Zimmermann, M. H., Milburn, J. A. (eds.) Transport in plants. I. Phloem transport. Encyclopedia of plant physiology. Springer-Verlag, Berlin, p 260-286

Henley, W. J. (1993). Measurement and interpretation of photosynthesis light-response curves in algae in the context of photoinhibition and diel changes. J. Phycol. 29: $729-739$

Jackson, M. B., Drew, M. C. (1984). Effect of flooding on growth and metabolism of herbaceous plants. In: Kozlowski, T. T (ed.) Flooding and plant growth. Academic Press, Orlando, p. 47-128

Jassby, A. D., Platt, T. (1976). Mathematical formulation of the relationship between photosynthesis and light for phytoplankton. Limnol. Oceanogr. 21: 540-547

Kenworthy, W. J., Fonseca, M. S., DiPiero, S. J. (1991). Defining the ecological light compensation point for seagrasses Halodule wrightii and Syringodium filiforme from long term submarine light monitoring in the southern Indian River In: Kenworthy, W. J., Haunerts, D. E. (eds.) Results and recommendations of a workshop convened to examine the capability of water quality criteria, standards and monitoring programs to protect seagrasses from deteriorating water transparency. Final report. South Florida Water Management District, West Palm Beach, p. $98-105$

Kirk, J. T. O. (1983). Light and photosynthesis in aquatic ecosystems. Cambridge University Press, Cambridge

Kraemer, G. P., Alberte, R. S. (1993). Age-related patterns of metabolism and biomass in subterranean tissues of Zostera marina L. (eelgrass). Mar Ecol. Prog. Ser 95: 193-203

Kremer, J. N., Nixon, S. W. (1978). A coastal marine ecosystem. Simulation and analysis. Springer-Verlag, Berlin

Larkum, A. W. D., West, R. J. (1990). Long-term changes of seagrass meadows in Botany Bay, Australia. Aquat. Bot. 37: $55-70$

Lüning, K. Dring, M. (1979). Continuous underwater light measurement near Helgoland (North Sea) and its significance for characteristic light limits in the subtidal region. Helgoländer wiss. Meeresunters. 32: 403-424

McBride, G. B. (1992). Simple calculation of daily photosynthesis by means of five photosynthesis-light equations. Limnol. Oceanogr. 37: 1796-1808

McMahon, T G., Raine, R. C. T., Fast, T., Kies, L., Patching, J. W. (1992). Phytoplankton biomass, light attenuation and mixing in the Shannon Estuary, Ireland. J. mar. biol. Ass. U.K. 72: 709-720

McPherson, B. F., Miller, R. L. (1993). Causes of light attenuation in estuarine waters of southwestern Florida. In: Morris, L., Tomasko, D. (eds.) Proceedings and conclusions of workshops on: submerged aquatic vegetation 
initiative and the photosynthetic active radiation workshops. Indian River National Estuary Program, St. Johns River Water Mgmt Dist., Palatka, FL, p. 239-246

Monroe, M. W., Kelly, J., Lisowski, N. (1992). State of the estuary. A report on conditions and problems in the San Francisco Bay/Sacramento-San Joaquin Delta estuary. San Francisco Bay Estuary Project, Oakland, CA

Mornis, L., Tomasko, D. (1993). Proceedings and conclusions of workshops on: submerged aquatic vegetation initiative and the photosynthetic active radiation workshops. Indian River National Estuary Program, St. Johns River Water Mgmt Dist,, Palatka, FL

Morris, L., Virnstein, R. (1993). PAR/SAV Workshop: summary and conclusions. In: Morris, L., Tomasko, D. (eds.) Proceedings and conclusions of workshops on: submerged aquatic vegetation initiative and the photosynthetic active radiation workshops. Indian River National Estuary Program, St. Johns River Water Mgmt Dist., Palatka, FL, p. $237-243$

Onuf, C. (1991). Light requirements for Halodule wrightii, Syringodium filiforme, and Halophila englemanni in a heterogeneous and variable environment inferred from long-term monitoring. In: Kenworthy, J. W., Haunert, D. E. (eds.) The light requirements of seagrasses. Results and recommendations of a workshop. NOAA Tech. Memo. NMFS-SEFC-287. U.S. Nat. Marine Fish. Serv. (NOAA), Beaufort, NC, p. 95-105

Orth, R. J., Moore, K. A. (1983). Chesapeake Bay: an unprecedented decline in submerged aquatic vegetation. Science 222: $51-53$

Ostenfeld, C. H. (1908). On the ecology and distribution of the grass-wrack (Zostera marina) in Danish waters. Report of the Danish Biological Station, Copenhagen

Pinckney, J. L., Zingmark, R. G. (1993). Modeling the annual production of intertidal benthic microalgae in estuarine ecosystems. J. Phycol. 29: 396-407

Rastetter, E. B., King, A. W., Crosby, B. J., Hornberger, G. M., O'Neill, R. V., Hobbie, J. E. (1992). Aggregating fine-scale ecological knowledge to model coarser-scale attributes of ecosystems. Ecol. Appl. 2: 55-70

Richardson, K., Beardall, J., Raven, J. A. (1983). Adaptation of unicellular algae to irradiance: an analysis of strategies. New Phytol. 93: 157-191

Saglio, P. H. (1985). Effect of path or sink anoxia on sugar translocation in roots of maize seedlings. Plant Physiol. 77 : $285-290$

Shepherd, S. A., McComb, A. J., Bulthuis, D. A., Neverauskus, V., Steffensen, D. A., West, R. (1989). Decline of seagrasses. In: Larkum, A. W. D., McComb, A. J., Shepherd, S. A. (eds.) Biology of seagrasses. A treatise on the biology of sea-

This article was submitted to the editor grasses with special reference to the Australian region. Elsevier, Amsterdam, p. 346-393

Siegel, D. A., Dickey, T. D. (1987). Observations of the vertical structure of the diffuse attenuation coefficient spectrum. Deep Sea Res. 34: 547-563

Smith, R. D. (1989). Anaerobic metabolism in the roots of the seagrass Zostera marina L. Ph.D. dissertation. The University of Chicago

Smith, R. D., Dennison, W. C., Alberte, R. S. (1984). Role of seagrass photosynthesis in root aerobic processes. Plant. Physiol. 74: 1055-1058

Stewart, J., Van Arman, J. (1987). The Indian River Lagoon Joint Reconnaissance Report. Dept Env. Reg., OCRM, NOAA, Ft. Pierce, FL

Stross, R. G., Sokol, R. C. (1989). Runoff and flocculation modify underwater light environment of the Hudson River Estuary. Estuar. coast. Shelf Sci. 29: 305-316

Thornley, J. H. M., Johnson, I. R. (1990). Plant and crop modeling. A mathematical approach to plant and crop physiology. Clarendon Press, Oxford

Valiela, I., Foreman, K., LaMontagne, M., Hersch, D., Costa, J., Peckol, P., Demeo-Anderson, B., D'Avanzo, C., Babione, M., Cham, C., Brawley, J., Lajtha, K. (1992). Couplings of watersheds and coastal waters: sources and consequences of nutrient enrichment in Waiquoit Bay, Massachusetts. Estuaries 15: 443-457

Webb, W. L., Newton, M., Starr, D. (1974). Carbon dioxide exchange of Alnus rubra: a mathematical model. Oecologia 17: $281-291$

Wetzel, R. L., Neckles, H. (1986). A model of Zostera marina L. photosynthesis and growth: simulated effects of selected physical-chemical variables and biological interactions. Aquat. Bot. 26: 307-323

Wilkinson, L. (1990). SYSTAT: the system for statistics. Systat, Inc., Evanston, IL

Zieman, J. C. (1975). Tropical sea grass ecosystems and pollution. In: Wood, E. F., Johannes, R. E. (eds.) Tropical marine pollution. Elsevier, New York, p. 63-74

Zimmerman, R. C., Reguzzoni, J. L., Wyllie-Echeverria, S., Josselyn, M., Alberte, R. S. (1991). Assessment of environmental suitability for growth of Zostera marina L. (eelgrass) in San Francisco Bay. Aquat. Bot. 39: 353-366

Zimmerman, R. C., Smith, R. D., Alberte, R. S. (1987). Is growth of eelgrass nitrogen limited? A numerical simulation model of the effects of light and nitrogen on the growth dynamics of Zostera marina. Mar. Ecol. Prog. Ser. $41 \quad 167-176$

Zimmerman, R. C., Smith, R. D., Alberte, R. S. (1989). Thermal acclimation and whole plant carbon balance in Zostera marina L. (eelgrass). J. exp. mar. Biol. Ecol. 130: 93-109

Manuscript first received: February 1, 1994

Revised version accepted: August 5, 1994 